\title{
DESIGN OF AUTOMATED PRESSURE CONTROL SWITCH FOR BORE-HOLE, USING VISUAL BASIC PROGRAMMING LANGUAGE
}

\author{
G. I. Nwandikom ${ }^{1}$, K. N. Nwaigwe ${ }^{2}$, O. Isibor $^{3}$ \\ ${ }^{I}$ Department of Agricultural Engineering, Federal University of Technology, Owerri Nigeria \\ ${ }^{2}$ Department of Agricultural Engineering, Federal University of Technology, Owerri Nigeria \\ ${ }^{3}$ Department of Agricultural Engineering, Federal University of Technology, Owerri Nigeria
}

\begin{abstract}
An Automatic bore-hole control system is designed.In all life endeavors water is needed for various purposes. In the recent time, bore-hole systems are mostly the source of portable water. Hence an automatic bore-hole control system is important in order to reduce drudgery, extra labor cost on bore-hole operation, unnecessary water loss and bottle necks in production process as a result of the lag time in starting the pump for tank refill. A spring loaded pressure control system is used in this design in contrast to floats used in similar control set ups, and is proven to be more effective and reliable. When the tank is empty the pump switches on, and when full switches off automatically. The Visual Basic programming provides an easy means of calculating spring constant needed for various heights. The device can be used for any shape of tank.
\end{abstract}

Keywords: Borehole, Control System, Water, Switch, Visual Basic

\section{INTRODUCTION}

Water is a very important commodity in all production processes and life in general. Every agricultural firm or industry utilizes water in majority of its processes. Water is vital to human life and survival, the adult human body needs to take in 1.7 litres (3 pints) of water every day. According to health sources, without food and water life can come to an end in about 2 weeks, however without food but with access to water only, man can live for over 8 weeks. Reliability and availability of water supply therefore can not be over emphasized. In domestic activities, interrupted water supply could be detrimental, for instance when one is showering. The need becomes more pressing in an industry or farm setting. In the farm setting, for instance in the raising of live-stock where high levels of automation is involved in water supply, when there is lack of water in the water tank, the animals could develop illness. Also in fish farming particularly in the hatchery and breeding trough where discharge and refilling of the pond is done automatically, there ought to be constant availability of water in the water tank. In a case where an operator (to operate the pump, i.e. switch on and off) is not available there could be serious loss on the part of the owner of the farm.

Over the years different people have sought for different ways to ease water supply. Among the early devices for lifting water from streams to higher-lying fields was the Egyptian shadoof, which is a bucket set on one end of a counterweighted pole. The Archimedes' screw, used for the same purpose, is a cylinder containing a wide-threaded screw turned by hand. The cylinder was set on an incline with the lower end in the stream, and as the screw was turned it lifted water to a higher level. The Persian wheel, still in use in India today, is a partly submerged vertical wheel with buckets attached to the rim. As the wheel is turned by draught animals rotating a geared horizontal wheel, the buckets are filled and emptied into a trough above that carries the water to crop-sown fields. (Microsoft ® Encarta $®, 2006)$

According to Michael (1998) several types of indigenous water lifts are in vogue in India and may be manuallyoperated or animal-operated. Based on the optimum range in the height of lift, they may be grouped under devices for low lift, medium lift and high lift. The Swing Basket, the Don, the Archimedean screw and the Water Wheel are all low head water lifts. They are suitable when the depth to water surface does not exceed 1.2 metres. Medium head water lifts are suitable when the height of lift is within the range of 1.2 to 10 metres and they include the Persian wheel, Chain pump, leather bucket lift with self-emptying bucket, circular two-bucket lift and the counterpoise-bucket lift. High head water lifts are necessary when the height of lift is above 10 metres. The only indigenous water lift suitable for deep wells is the rope and bucket lift (charasa) operated by bullocks. The device may be operated singly or in multiples of two or more working simultaneously, depending on the yield of the well and the requirement of irrigation water.

Positive displacement pumps discharge the same volume of water regardless of the head against which they operate. This type of pump must be powered to meet the maximum load resulting from its discharge capacity and the greatest head under which it will operate. They are commonly used in home water supply systems, well drilling and under special situations in irrigation pumping. Reciprocating pumps, sometimes called piston or displacement pumps, function by means of a piston movement which displaces water in a cylinder. The flow is controlled by valves. A 
piston or plunger is a cylindrical piece which moves backward and forward inside a hollow cylinder. The capacity of the reciprocating pump depends on the size of the cylinder chamber and the length and speed of stroke. Numerous forms of packings are used to prevent leakages past a piston. Cup-leathers are usually used for packing in case of pump cylinders. The pressure of water acting inside the cup presses the leather outwards against the cylinder thus preventing leakage.

Aderounmu et al (1998) worked on an agent-based approach to water distribution system control using Borland $\mathrm{C}++$ programming language to achieve a pressure sensitive on and off switch for a bore-hole system.

However this work is dealing with a mechanized way of making and breaking a circuit using pressure as a result of water levels. This design is far cheaper and provides rural farmers the opportunity of having access to this kind of control switch. Similarly, the visual basic programming language is used for calculations in the design. A graphic user interface is developed to make estimations easy for even uneducated technicians.

\section{MACHINE PARTS SELECTION AND}

\section{ARRANGEMENT}

The control switch housing (casing) is made of Teflon (polytetrafluoroethylene). Inside it is a brass piston to which is connected two shafts (connecting rod) with a displacement of $X_{o}$ from each other. There is also a spring of known stiffness, two rubber seals to restrain water leakages, and a normal electric switch (see figure 1). The device is to be placed at the bottom of the tank to which it is meant to control its water level at the source of water outlet.

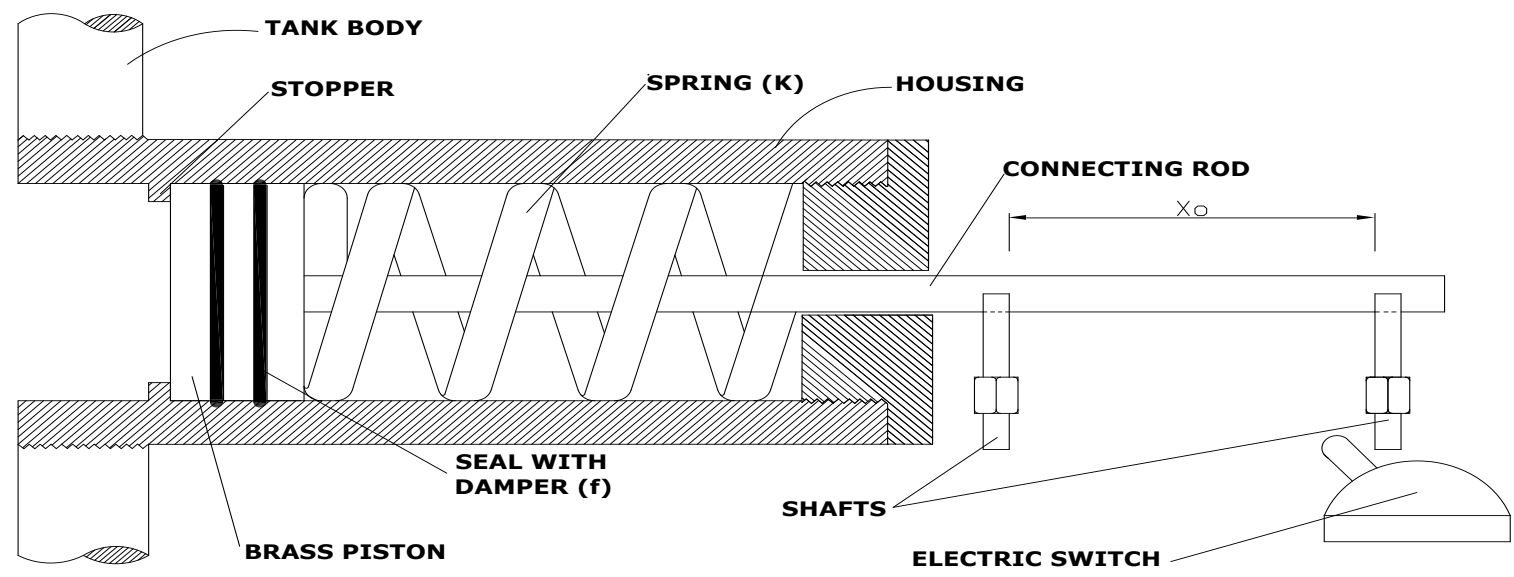

Fig.1 Pressure Controlled Switch

\subsection{Housing/Casing}

The housing/casing is made basically of polytetrafluoroethylene (Teflon). The choice is because it is very light in weight, self lubricating, has a waxy feel, low coefficient of friction, moderate tensile strength (2500 4000psi) and a good heat resistance. The coefficient of friction between the seal and Teflon is 0.192 (dry state) and
0.336 (wet state). Its melting point is $327^{\circ} \mathrm{C}$ and it has excellent weathering and chemical resistance (Ghosh, 2004). A hexagonal bolt is screwed into one end of the housing. Glue was rubbed around the thread before screwing in the case into the tank. A $12 \mathrm{~mm}$ hole is drilled through the hexagonal bolt to allow the brass shaft (connecting rod) passage, as shown in figure 2 .

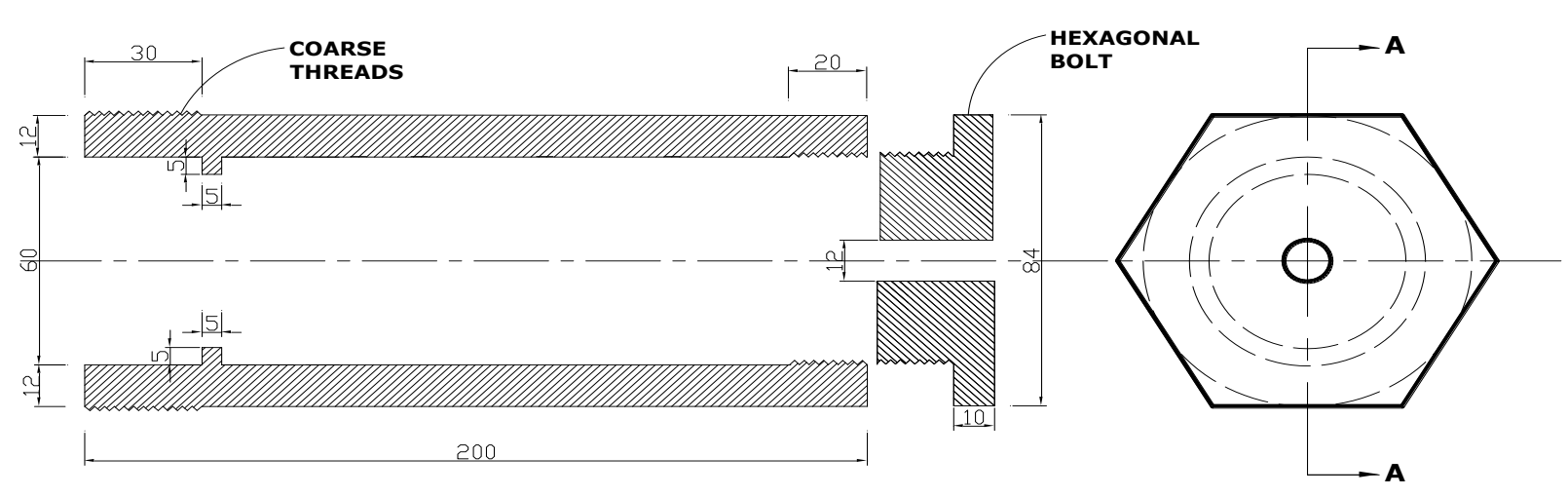

Fig. 2: Housing of the Pressure Controlled Switch (all dimensions in mm). 


\subsection{The Piston}

The Piston is made of brass, because brass dose not rust (a non -ferrous metal) (Deanna, 1976; Ojha and Michael, 2003). A $3.0 \mathrm{~mm}$ of $1.5 \mathrm{~mm}$ depth groove is made in piston as indicated, to provide a seat for the seals. Two seals are used to ensure water tight housing. Two cylindrical shafts (with a hexagonal cross-sectional shape towards the top and a square/rectangular shape at the tip just above the hexagonal shape) are screwed into the long shaft/connecting rod (which connects to the piston) at $90 \mathrm{~mm}$ interval. Glue is used to fasten the shaft into place. (Note: this is done after the piston must have been placed in the housing and the hexagonal bolt, figure 3, tightened as appropriate).
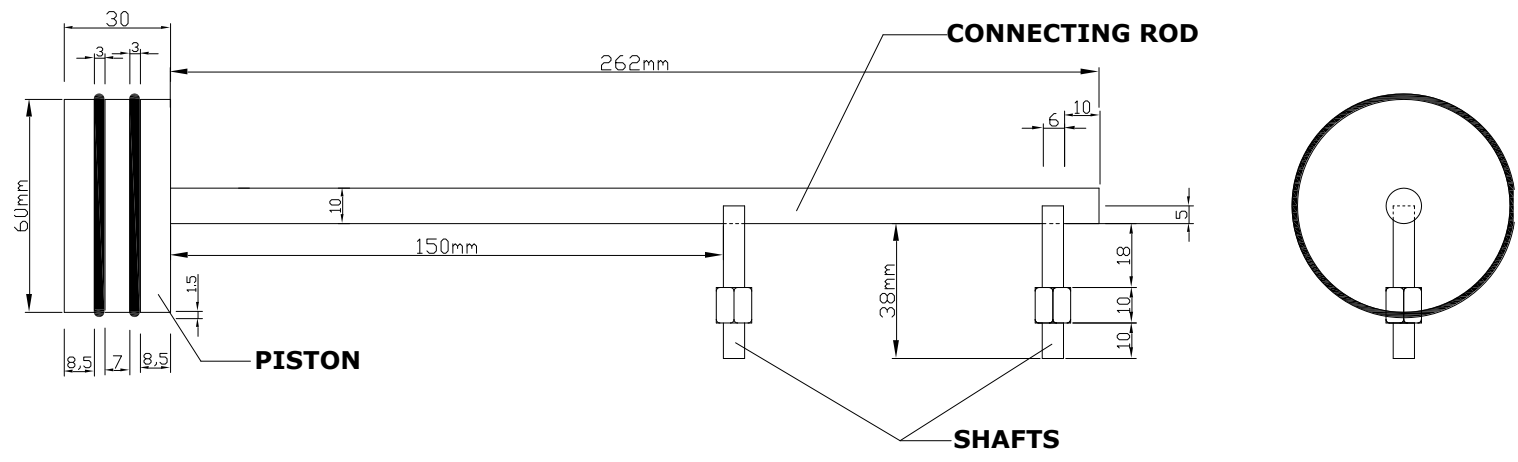

Fig. 3: Arrangement of Pressure Controlled Switch

\subsection{The Seal}

The seal as mentioned above is made of natural rubber (Styrene-Butadiene rubber, SBR).

Originally produces by the United States government as GR-S (Government rubber-Styrene), they are copolymers of styrene and butadiene with the styrene content usually $23.5 \%$ wt. because of the random arrangements of the monomers in the chain. SBR cannot crystallize on stretching hence carbon black or other reinforcing fillers are required to develop high tensile strength values. (Katchy, 2000).

\subsection{Switch}

A normal household switch is placed at off position between the shafts (in figure 3) just before the extreme shaft (shaft 2) with a clearance of between $0-1 \mathrm{~mm}$.

\subsection{Spring}

The spring is made of brass with spring constant $\mathrm{k}$ as determined from the design calculations based on pressure exerted on piston.

\section{DESIGN CALCULATIONS}

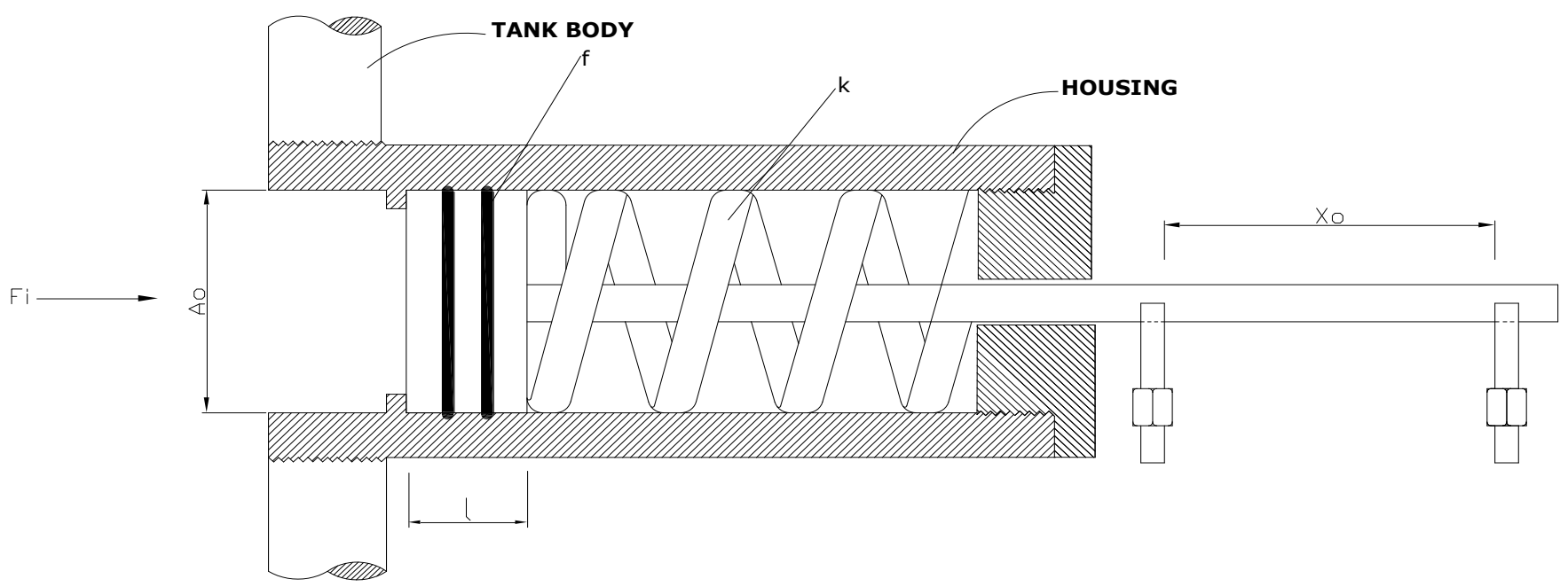

Fig. 4: Diagram Showing Parameters of Design 
According to Haslam, et al (1981), for a second order spring, mass and damper system we have;

$$
F_{i}=\frac{m^{2} x_{0}}{{d t^{2}}^{2}}+k x_{0}+\frac{f d x_{0}}{d t}
$$

At constant velocity $\frac{\mathrm{d}^{2} \mathrm{x}_{0}}{\mathrm{dt}^{2}}=0$

Note: The rate of refill is constant since the pump works at the same speed all through the pumping action except in a case of power surcharge.

Therefore;

$$
\begin{gathered}
\mathrm{F}_{\mathrm{i}}=0+\mathrm{kx}_{\mathrm{o}}+\frac{\mathrm{fdx_{0 }}}{\mathrm{dt}} ; \mathrm{F}_{\mathrm{i}}=\mathrm{kx}_{\mathrm{o}}+\mathrm{F} \\
\mathrm{F} \text { (friction force) }=\underline{\mathrm{fdx}}_{\underline{\mathrm{dt}}} \text { or } \mathrm{fV}_{\mathrm{o}}
\end{gathered}
$$

where;

$\mathrm{F}_{\mathrm{i}}=$ Input force due to water pressure as a result of water level in tank $(\mathrm{H})$.

$\mathrm{k}=$ spring constant.

$\mathrm{f}=$ damping constant.

$\mathrm{A}_{\mathrm{o}}=$ surface area of piston.

$\mathrm{X}_{\mathrm{o}}=$ displacement of piston with respect to height differences

$\underline{\mathrm{dx}}_{\mathrm{o}}=$ rate of displacement of piston during tank refill, with reference

$\mathrm{dt} \quad$ to rate of tank refill.

$l=$ distance between the seals (as indicated in figure 4)

$$
\mathrm{f}=\underline{\mathrm{F}}_{\mathrm{V}}---------(5)
$$

Where; $\mathrm{V}_{\mathrm{o}}=$ velocity of piston $=\underline{\mathrm{dx}}_{\mathrm{o}}$

$\mathrm{dt}$

$\mathrm{F}=$ friction force

$$
\mathrm{F}=\mu \mathrm{N}=\underline{\mathrm{fdx}}_{\mathrm{dt}}
$$

$\mathrm{N}=$ normal reaction equivalent to weight of piston,

$\mu=$ coefficient of friction between rubber seal and Teflon (0.192)

$$
\mathrm{N}=\mathrm{Mg}
$$

$\mathrm{M}=$ Mass of brass in $\mathrm{Kg}$;

$\mathrm{g}=$ acceleration due to gravity in $\mathrm{m} / \mathrm{s}^{2}$.

$$
\rho=\frac{M}{V}=\text { density of brass }
$$

Where;

$\mathrm{V}=$ Volume of brass

$$
\begin{aligned}
\mathrm{M} & =\rho \mathrm{V} \\
\mathrm{V}_{\mathrm{b}} & =\mathrm{A}_{\mathrm{o}} l- \\
\mathrm{A}_{\mathrm{o}} & =\frac{\Pi \mathrm{nd}_{\mathrm{o}}}{4}
\end{aligned}
$$

$\rho_{\mathrm{b}}=$ density of brass $=8,900 \mathrm{~kg} / \mathrm{m}^{3}$ (Okeke and Anyakoha, 1989)

$$
\begin{aligned}
& \mathrm{M}=\mathrm{V}_{\mathrm{b}} \rho_{\mathrm{b}}=\mathrm{A}_{\mathrm{o}} l \rho_{\mathrm{b}} \\
& \mathrm{N}=\mathrm{Mg}=\mathrm{A}_{\mathrm{o}} l \rho_{\mathrm{b}} \mathrm{g} \\
& \mathrm{F}=\mathrm{A}_{\mathrm{o}} l \rho_{\mathrm{b}} \mathrm{g} \mu-
\end{aligned}
$$

To determine $\mathrm{k}$ from equation (3);

$$
\begin{aligned}
& \mathrm{kx}_{\mathrm{o}}=\mathrm{F}_{\mathrm{i}}-\mathrm{F} \\
& \mathrm{k}=\frac{\mathrm{F}_{\mathrm{i}}-\mathrm{F}}{\mathrm{X}_{\mathrm{o}}}-\cdots
\end{aligned}
$$

$F_{i}$ is input force that will cause a displacement of $x_{0}$

According to Okeke and Anyakoha (1989), we can summarize the characteristics of pressure in a liquid as follows:

- The pressure in a liquid increases in direct proportion to the depth of the liquid.

- The pressure in different liquids at the same depth varies directly with density.

- $\quad$ The pressure at any point in the liquid acts equally in all directions.

- $\quad$ The pressure at all points at the same level within a liquid is the same.

$$
F_{i}=\rho_{\mathrm{o}} H_{1} A_{o} g
$$

where;

$\mathrm{g}=$ acceleration due to gravity $=9.81 \mathrm{~m} / \mathrm{s}^{2}$

$\mathrm{H}_{\mathrm{i}}=$ highest allowable position of water level.

$\rho_{\mathrm{o}}=$ density of water $=1000 \mathrm{~kg} / \mathrm{m}^{3}$ (Okeke and Anyakoha, 1989)

Fromequation (17);

$$
\mathrm{F}_{\mathrm{i}}=27.7 \mathrm{H}_{1}
$$

From equation (16);

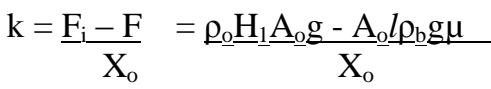

$$
\begin{aligned}
& \mathrm{k}=\underline{\mathrm{A}}_{\mathrm{o}} \mathrm{g}\left(\underline{\rho}_{\mathrm{o}} \underline{\mathrm{H}_{1}} \underline{\mathrm{X}}_{\mathrm{o}}-l \rho_{\mathrm{b}} \underline{\mu}\right)
\end{aligned}
$$

\subsection{Input Required}

Equation (20) is the required model. The only input required is the height of tank $\mathrm{H}$ (excluding the cover). 


$$
\mathrm{H}_{1}=\mathrm{H}-0.1
$$

$0.1 \mathrm{~m}(10 \mathrm{~cm})$ is the clearance of the tank height while the active height is $\left(\mathrm{H}_{1}\right)$.

\subsection{Lowest Possible Depth $\left(\mathrm{H}_{2}\right)$}

From the switch geometry, the pump will be activated at $\mathrm{x}_{\mathrm{o}}$ $\geq 10 \mathrm{~mm}$; i.e. $0.01 \mathrm{~m}$. The damping coefficient factor $\mathrm{f}$ (i.e. $\mathrm{fdx}_{\mathrm{o}} / \mathrm{dt}$ ) is neglected since the rate of discharge (i.e. $\mathrm{dx}_{\mathrm{o}} / \mathrm{dt}$ ) is irregular.

$$
\mathrm{F}_{\mathrm{i}}=\mathrm{kx}_{\mathrm{o}}
$$

$$
\rho \mathrm{H}_{2} \mathrm{~A}_{\mathrm{o}} \mathrm{g}=\mathrm{k}(0.01)
$$

From equation (18);

$$
27.7 \mathrm{H}_{2}=0.01 \mathrm{k}
$$$$
\mathrm{H}_{2}=(0.01 / 27.733) \mathrm{k}
$$

$$
\mathrm{H}_{2}=(0.000361) \mathrm{k}
$$

\section{PROGRAMMING IN VISUAL BASIC}

\subsection{Graphic User Interface (GUI)}

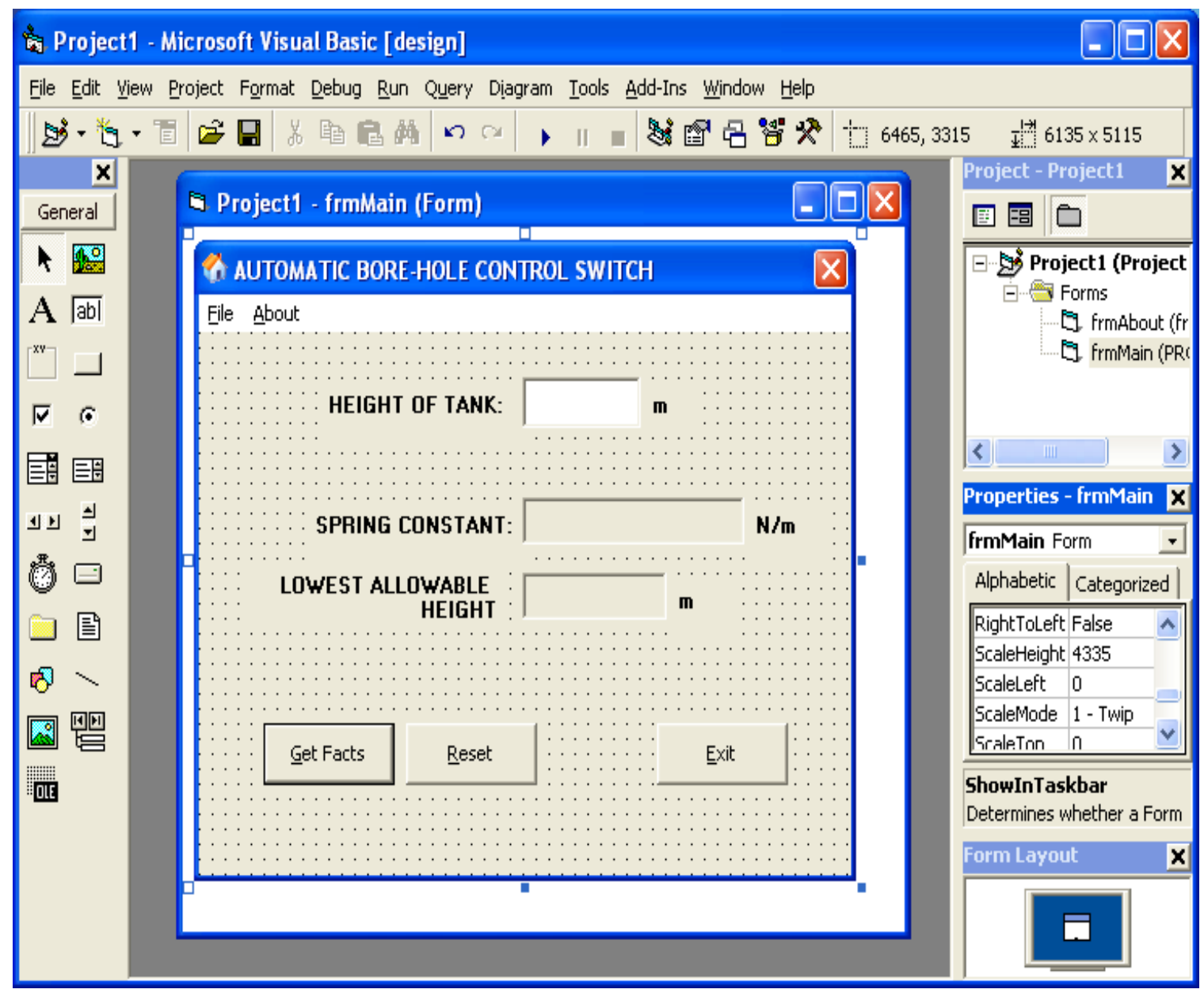

Plate1: Graphic User Interface (GUI)

This interface connects the user of the program to the codes that run the program. It contains all the graphic designs put by the designer of the program that allows you input values to get an output after an event. The interface is as shown in plate 1. It has three command buttons named; Get Facts, Reset and Exit. It has a text box for the user of the program to input the height of tank in meters, and two menu buttons - namely "File and About". The file menu contains three sub menus - namely "Get Facts, Diagrams and Exit". The diagrams submenu contains three other sub menus namely Pressure controlled switch, Housing for the pressure controlled switch and Arrangement of a pressure controlled switch. The About menu button opens an about dialogue box describing the abstract of this work (See plate 2 below). There are indented labels where the design results would display after the "Get Facts" command button is clicked.

The Reset button resets the program, while the exit button exist the window. All these are arranged on a form as shown above. 


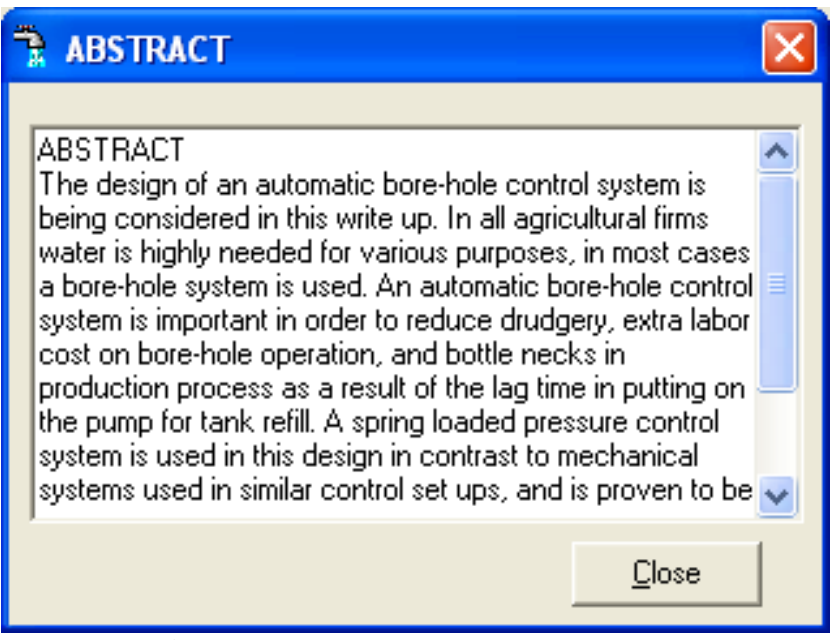

Plate 2: About Dialogue Box Showing Abstract

\subsection{Program Code}

The code was formatted according to standard visual basic programming rule as below:

'Name of Object . Property = Value' (Julia and Anita, 2000)

The program code used to execute this program gives:

i. The spring constant $(\mathrm{k})$ required to be used for a certain tank height $(\mathrm{H})$.

ii. The lowest possible allowable height $\left(\mathrm{H}_{2}\right)$.

The code solves equations (20) and (24) to achieve the above purposes.

\section{CONCLUSION}

Based on the result of this study the following conclusions were drawn:
i. A seal is required to avoid water leakage
ii. The spring to be used depends on the size of tank
iii. The device can be used for any shape of tank.
iv. The rate of filling does not affect the on and off process of the switch.
v. Visual Basic programming simplifies the process of determining the spring constant needed for different heights or water level.

\section{REFERENCES}

[1] Aderounmu G. A., Adagunodo, E. R., Akintola, A. A., Adetoye A.O., 1998. An agent based Approach to water Distribution System Control, Journal of Agricultural Engineering and Technology, Vol. 6, pp. 39-46.

[2] Deanna S., 1976 Auto Repair for Dummies, Published by Mc Graw Hill Book Company, New York, p 164

[3] Encartar Reference Encyclopedia, 2006; Microsoft/Automation of water supply.

[4] Ghosh, P. 2004; Polymer Science and Technology, Tata Mc Graw - Hill., India (New Delhi); pp 325,436
[5] Haslam J. A., Summers G. R., Williams D., 1981. Engineering Instrumentation and Control, Edward Arnold (Publishers) Ltd. London, p. 179.

[6] Julia K. and Anita P. 2000. Programming In Visual Basic 6.0, Mc Graw-Hill Book Company New York.

[7] Katchy E. M., 2000; Introduction to Polymer Technology, EL' Denmark Ltd., Nigeria; p. 209

[8] Michael A. M., 1998; Irrigation: Theory and Practice, Vikas Publishing House PVT Ltd, New Delhi, pp 196 - 207.

[9] Ojha T. P. and Michael A. M., 2003, Principles of Agricultural Engineering, Jain Brothers, new Delhi pp. 284, 286.

[10] Okeke P. N. and Anyakoha M. W., 1989, Senior Secondary Physics, Published by Macmillian Education Ltd, London, pp 16, 24, 170.

[11] Tipler P. A. 1976. Physics, Worth Publishers Inc. New York, pp. 126, 128, 157. 